\title{
PENINGKATAN KUALITAS HIDUP PASIEN KANKER PAYUDARA MELALUI PROGRAM BESTCARE (BREAST CANCER WOUND AND PALLIATIVE CARE)
}

\author{
Fitria Endah Janitra ${ }^{1}$, Kurnia Wijayanti ${ }^{2}$, Indah Sri Wahyuningsih ${ }^{3}$, \\ Hani Werdi Apriyanti ${ }^{4}$ \\ ${ }^{1}$ Universitas Islam Sultan Agung \\ email: fitria.janitra@gmail.com \\ 2Universitas Islam Sultan Agung \\ email: jayahe28@gmail.com \\ ${ }^{3}$ Universitas Islam Sultan Agung \\ email: indah.unissula@gmail.com \\ ${ }^{4}$ Universitas Islam Sultan Agung \\ email: hani.apriyanti@unissula.ac.id
}

\begin{abstract}
The incidence of breast cancer increase every year, if didn't controlled by the WHO estimates that there will be an increase of $30 \%$ and $70 \%$ in 2030. The patients often experience are complex problems such as the lack of self-confidence, pain in wounds and aesthetic problems. Postoperative patients or chemotherapy need proper care in order to achieve a good quality of life. The BESTCARE program aims to improve the quality of life of breast cancer patients through activities that can be carried out by cadres and patients. The methods was lectures, demonstrations and practices. While the media used are lectures, demonstrations, practices and wound care. The material presented includes the incidence of breast cancer, understanding, risk factors, conscious examination steps, wound care with modern dressing. Results: The team succeeded in forming a cancer care health, knowledge and understanding of the cadre of mam health increased from $50 \%$ to $85 \%$, health cadres were able to make conscious movements from before $55 \%$ to $90 \%$, an increase in the number of visits, decreased pain scale and wound care progress with modern dressing. Conclusion: The program of activities carried out by the Bestcare team was able to be carried out properly and as expected improving the quality of life in palliative patients both in the clinic or home visit.
\end{abstract}

Keywords: breast cancer; quality of life; bestcare

\begin{abstract}
ABSTRAK
Insiden penyakit kanker payudara meningkat setiap tahunnya, jika tidak segera dikendalikan WHO memperkirakan akan terjadi peningkatan 30\% dan 70\% ditahun 2030. Pasien kanker payudara seringkali mengalami permasalahan yang cukup kompleks yaitu kurangnya rasa percaya diri, nyeri pada luka dan masalah estetika. Pasien paska pembedahan ataupun kemoterapi membutuhkan perawatan yang tepat agar tercapai kualitas hidup yang baik. Program BESTCARE bertujuan untuk meningkatkan kulaitas hidup pasien kanker payudara melalui kegiatan-kegiatan yang dapat dilakukan oleh kader dan pasien. Metode yang dilakukan adalah ceramah,
\end{abstract}


demonstrasi dan praktik. Sedangkan media yang digunakan adalah ceramah, demonstrasi, praktik dan tindakan rawat luka. Materi yang disampaikan meliputi angka kejadian kanker payudara, pengertian, faktor resiko, langkah pemeriksaan sadari, tindakan rawat luka dengan modern dressing. Hasil: Tim berhasil membentuk kader kesehatan peduli kanker, pengetahuan dan pemahaman kader kesehatan mamyang meningkat dari 50\% menjadi 85\%, kader kesehatan mampu melakukan gerakan sadari dari sebelum 55\% menjadi 90\%, terjadi pengingkatan jumlah kunjungan, penurunan skala nyeri dan progress perawatan luka dengan modern dressing. Kesimpulan: Program kegiatan yang dilakukan tim Bestcare mampu terlaksana dengan baik dan sesuai yang diharapkan untuk meningkatkan kualitas hidupnya pada pasien paliatif baik di klinik ataupun home visit.

Kata Kunci : kanker payudara; kualitas hidup; bestcare

\section{PENDAHULUAN}

Kanker merupakan salah satu penyebab kematian tertinggi dan menjadi masalah kesehatan di dunia maupun di Indonesia. World Health Organization (2013) menyatakan bahwa insiden penderita kanker payudara pada tahun 2012 sebanyak 1,7 juta wanita. Pada tahun 2013 ditemukan 2.240 kasus baru dan setiap tahun jumlah penderita kanker payudara bertambah 7 juta orang, jika tidak segera dikendalikan WHO memperkirakan pada tahun 2030 rata-rata penderita kanker di dunia akan naik sebesar $30 \%$ dan $70 \%$ penyumbangnya adalah negara berkembang termasuk Indonesia (Kemenkes RI, 2013). Menurut (Kemenkes RI, 2015), prevalensi kanker payudara di Indonesia mencapai 0,5\% dari 1000 perempuan. Kanker payudara stadium lanjut memiliki masalah yang kompleks dalam penanganannya karena selain masalah fisik, pasien juga menghadapi masalah respon psikologis yang juga memerlukan penanganan khusus. Strategi perawatan yang tepat merupakan prioritas utama untuk memperbaiki kualitas hidup pasien kanker.

Perawatan paliatif merupakan pendekatan yang bertujuan untuk meningkatkan kualitas hidup pasien dan memberikan dukungan bagi keluarga yang menghadapi masalah yang berhubungan dengan kondisi pasien dengan mencegah dan mengurangi penderitaan melalui identifikasi dini, penilaian yang seksama serta pengobatan nyeri dan masalah-masalah lain, baik masalah fisik, psikososial, spiritual dan pelayanan masa dukacita bagi keluarga (Piggin, 2007).Perawatan paliatif merupakan pelayanan kesehatan yang bersifat holistik dengan melibatkan berbagai profesi (LundNielsen et al, 2007).Implementasi perawatan paliatif yang harus diterapkan di rumah sakit meliputi penatalaksanaan nyeri, penatalaksanaan keluhan fisik, pemberian dukungan psikologis, sosial, dan spiritual (Lund-Nielsen et al, 2007).

Salah satu permasalahan kanker payudara yang memerlukan penanganan multi disiplin secara terpadu pada fase paliatif adalah terjadinya komplikasi berupa metastase, yaitu penjalaran sel kanker ke organ tubuh lain. Penjalaran kanker payudara ke bawah kulit akan membentuk lesi berupa 
malignant fungating wound. Lesi luka kanker terbentuk karena infiltrasi sel kanker ke daerah epitelium, kelenjer limfa dan pembuluh darah, terutama pembuluh darah kapiler (Tanjung, 2007). Penjalaran sel kanker selanjutnya akan merusak daerah kulit sekitar payudara dan menimbulkan ulserasi massa jamur (ulcerating fungating mass). Penemuan kanker payudara yang disertai luka kronis, memiliki masalah yang kompleks dalam penanganannya, karena kondisi pasien kanker payudara dengan luka, bukan saja terkait dengan masalah fisik / fisiologis, tetapi yang tidak kalah pentingnya adalah masalah respon psikologis yang juga memerlukan penanganan khusus (Kartika,2015). Dengan demikian, perawatan luka kanker merupakan tantangan tersendiri bagi perawatkarena luka kanker sulit untuk sembuh, akibat sel-sel kanker yang terus bertambah serta menimbulkan gejala yang sulit untuk ditangani, terkait dengan malodor, eksudat dan infeksi (Utari, 2012). Hasil penelitian melaporkan bahwa dampak negatif uka kronik adalah terjadinya perubahan gambaran diri, perasaan malu, menarik diri, menurunnya selera makan, gangguan pola tidur, gangguan interaksi sosial, serta gangguan dalam melaksanakan aktivitas spiritual (Wiksuarini, Rochmawati, \& Rahmah, 2018).

Keseluruhan permasalahan diatas biasanya juga melibatkan aspek estetika, hubungan perkawinan, sosial dan ekonomi. Kompleksnya permasalahan pasien dengan luka kanker payudara, baik permasalahan fisik maupun masalah psikososiospiritual lainnya, apabila tidak ditangani secara komprehensif akan menurunkan kualitas hidup pasien yang mungkin hanya tinggal beberapa minggu sampai beberapa bulan lagi (Utami, 2017), (Ketut \& Ariani, 2017).

Hasil studi pendahuluan yang dilakukan di Rumah Sakit Islam Sultan Agung (RSISA) yang merupakan salah satu mitra program ini, didapatkan dalam 1 (satu) bulan setidaknya terdapat 150-200 pasien kanker yang menjalani perawatan, baik untuk kemoterapi dan operasi pembedahan atau pengangkatan kanker. Mayoritas pasien kanker yang dirawat di RS. Islam Sultan Agung merupakan pasien kanker payudara.

Breast Cancer Wound and Palliative Care (BESTCARE) lahir tahun 2018 sebagai bentuk kepedulian dosen Fakultas IImu Keperawatan Unissula khususnya kepada pasien kanker payudara. Tim BESTCARE secara swadaya memberikan pelayanan perawatan luka pada pasien kanker payudara di sekitar kampus Unissula. Bestcare mendapatkan apresiasi dari Kemenristekdikti dengan mendapatkan hibah multi tahun dengan skema Program Pengembangan Usaha Produk Intelektual Kampus (PPUPIK) tahun 2019. PPUPIK merupakan sebuah unit usaha yang berbasis di kampus Unissula. BESTCARE melakukan pengembangan terhadap layanan yaitu melayani perawatan luka, konseling, manajemen nyeri dengan pendekatan perawatan paliatif baik di klinik dan di rumah pasien (homevisit).Tujuan dibentuknya BESTCARE yaitu agar pasien kanker dan penyakit kronis lainnya dapat menunjukkan peningkatan kualitas hidup. 


\section{METODE PELAKSANAAN}

Langkah yang dilakukan dalam pelaksanaan kegiatan ini adalah pembentukan kader kesehatan peduli kanker payudara, perawatan luka (wound care) dengan teknik moist dressing, pelayanan bebas nyeri (pain care) dan manajemen nutrisi pada pasien kanker payudara.

Pelaksanaan kegiatan ini dilakukan secara komprehensif pada pasien kanker payudara. Pertama, pembentukan kader peduli kanker dilakukan melalui pemberian materi tentang kanker payudarakemudian dilanjutkan dengan demonstrasi oleh pemateri dan praktek langsung. Media yang disiapkan oleh tim Bestcare adalah audio visual berupa materi tentang sadari dan langkah-langkahnya, dan leaflet. Materi pendidikan kesehatan meliputi pengertian payudara, pengertian, faktor resiko, mitos seputar kanker payudara, pentingnya pemeriksaan payudara sendiri (SADARI), waktu dilakukannya SADARI dan cara atau langkah-langkah memeriksanya.

Kedua, perawatan luka pada pasien kanker dan dengan penyakit luka kronis dilakukan oleh Tim Bestcare yang berjumlah 3 orang dengan keahlian di bidang keperawatan medikal bedah, keperawatan onkologi, dan keperawatan palliative yang sudah lulus dalam pelatihan rawat luka moden dengan sertifikasi dari Kementrian Kesehatan Republik Indonesia dan sertifikat kompetensi dari Indonesian ETNEP sehingga berhak mendapat gelar sebagai certified wound care clinician associate (CWCCA). Serta melibatkan 3 orang mahasiswa program ners yang sudah mendapatkan materi dan lulus dalam praktik rawat luka. Ketiga, layanan bebas nyeri dengan mengajarkan teknik relaksasi progresif pada pasien kanker menggunakan media flipchart.

\section{HASIL DAN PEMBAHASAN}

Kegiatan pengabdian masyarakat ini merupakan program dari pengabdian masyarakat Hibah Kemenristekdikti yang dilakukan kelurahan binaan yaitu di Kelurahan Bandarharjo, Semarang Utara dan rumah sakit mitra yaitu Rumah Sakit Islam Sultan Agung yang menghasilkan beberapa perubahan yang baik bagi pasien, diantaranya yaitu:

1. Terbentuknya kelompok kader kesehatan di 11 rukun warga (RW) di Kelurahan Bandarharjo, Semarang Utara dan berkomitmen untuk menyebarluaskan informasi secara aktif.

2. Kegiatan pembentukan kader kesehatan peduli kanker payudara mampu meningkatkan pengetahuan dan pemahaman kader tentang pemeriksaan payudara sendiri dari $50 \%$ menjadi $85 \%$.

3. Kader kesehatan juga terampil dan mampu melakukan gerakan sadari dengan urutan dan gerakan yang benar, dengan persentase sebelum $55 \%$ menjadi $90 \%$.

4. Peningkatan kunjungan pada pasien rawat luka dengan progress luka yang meningkat dari hari ke hari. 
5. Penurunan skala nyeri pada pasien kanker payudara yang dilakukan relaksasi otot progresif. Penilaian skala nyeri pada pasien dengan menggunakan instrumen penilaian Numeric Rating Scale (NRS).

6. Perawatan luka untuk pasien Bestcare menggunakan teknik perawatan luka modern (modern dressing). Perawatan luka modern sangat baik untuk mendukung perbaikan luka pada pasien kanker, karena luka pada pasien kanker mempunyai karakteristik yang berbeda dibandingkan dengan luka kronis lainnya. Selain itu dengan perawatan luka modern juga bisa menurunkan malodor, meningkatkan kenyamanan, dan menurunkan rasa nyeri, serta mencegah perdarahan dan maserasi pada pasien.

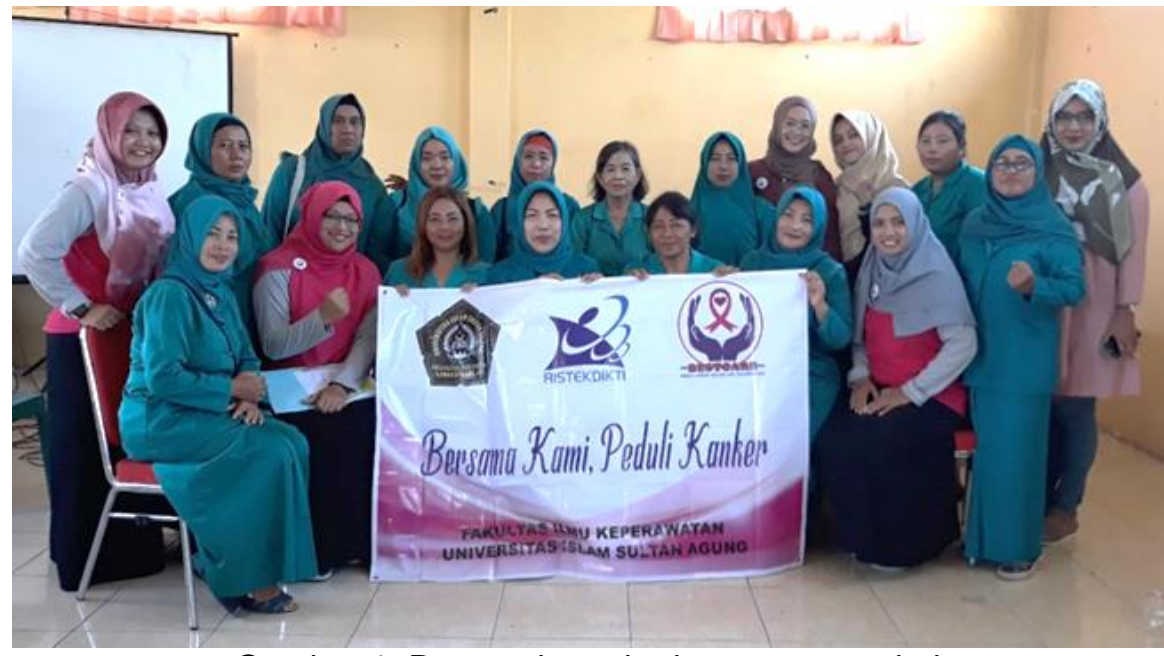

Gambar 1. Pengetahuan kader tentang sadari

\section{Grafik Kunjungan Bestcare}

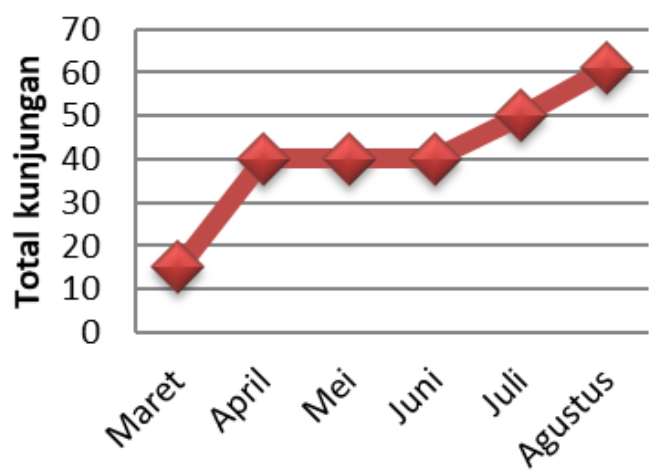

$\leadsto$ Pasien rawat luka

Gambar 2. Grafik Kunjungan Pasien BESTCARE bulan Maret sampai Agustus 2019 
Kegiatan BESTCARE yang dilakukan di masyarakat kelurahan binaan dan pasien mitra di rumah sakit islam memberikan pengaruh yang positif terhadap perubahan- perubahan yang terjadi pada masyarakat dan pasien, secara rinci perubahan yang terjadi dijelaskan sebagai berikut:

\section{Pembentukan Kader Kesehatan Peduli Kanker}

Kelurahan Bandarharjo memiliki luas wilayah $3,43 \mathrm{~km}^{2}$ ini terletak di Semarang Utara 50175 Provinsi Jawa Tengah. Kader kesehatan peduli kanker di wilayah Bandarharjo telah terbentuk melalui pemberian sosialisasi penyakit kanker payudara. Terdapat 50 kader yang terdiri dari 11 RW di Wilayah Bandarharjo, Semarang Utara yang menjadi kader kesehatan peduli kanker. Kader tersebut berperan dalam screening kanker payudara di wilayah Bandarharjo.

2. Peningkatan Pengetahuan dan Ketrampilan Kader mengenai Pemeriksaan Sadari

Kader Peduli kanker di wilayah Bandarharjo diberikan materi mengenai pengetahuan pemeriksaan sadari dengan uji paired t test menghasilkan nilai $p$ value 0.003 dengan makna bahwa pemberian materi mengenai pemeriksaan sadari cukup signifikan meningkatkan pengetahuan kader. Hasil tersebut menunjukkan nilai yang baik, dengan arti lain bahwa materi yang diberikan oleh tim mampu laksana diterima dengan baik oleh para kader kesehatan. Selain itu, setelah diberikan materi diberikan latihan mengenai cara pemeriksaan sadari yang bertujuan agar kader mampu ikut serta dalam screening tanda dan gejala kanker payudara. Ketrampilan kader meningkat dari $55 \%$ menjadi $90 \%$. Hal itu menunjukkan bahwa dengan adanya demonstrasi oleh tim BESTCARE dapat meningkatkan ketrampilan kader dalam melakukan pemeriksaan sadari untuk para warganya.

\section{Penurunan Skala Nyeri pada Pasien Kanker}

Skala nyeri pada pasien kanker diukur dengan lembar penilaian nyeri numeric rating scale. Skala nyeri menurun pada pasien yang diberikan terapi relaksasi otot progresif. Sebagian besar pasien belum terpapar dengan teknik relaksasi otot progresif. Relaksasi otot progresif adalah suatu terapi relaksasi yang diberikan kepada klien dengan menegangkan otot- otot tertentu dan kemudian relaksasi. Relaksasi otot progresif adalah salah satu cara dari teknik relaksasi yang mengombinasikan latihan napas dalam dan serangkaian seri kontraksi dan relaksasi otot tertentu. Dalam pelaksanaannya setelah dilakukan penilaian nyeri dengan relaksasi otot progresif menjadi menurun tingkat nyerinya. Pada laporan home visit, Tim mendapati pasien sedang melakukan teknik relaksasi otot progresif, nilai nyeri menurun karena tidak terjadi ketegangan otot dan menjadi lebih rileks. Teknik relaksasi otot progresif dilakukan berdasarkan standar operasional prosedur (SOP) yang telah berlaku. 


\section{Perawatan Luka Modern pada Pasien Kanker}

Luka pada pasien kanker mempunyai karakteristik yaitu luka atau jaringan sangat rapuh sehingga mudah mengalami perdarahan, malodor, banyak eksudat, nyeri, dan maserasi sehingga sangat berbeda dengan luka pada penyakit kronis lainnya. Manajemen eksudat diperlukan untuk mengendalikan jumlah eksudat. Jumlah eksudat berhubungan dengan ukuran luka, infeksi, nekrotik, sloughy (Regan, 2007).

Pada perawatan luka modern menggunakan bahan yang bisa mengurangi gejala tersebut, seperti penggunaan alginate, foam, obat topikal yaitu (vaselin, zink, metronidazole) yang berfungsi untuk menghentikan perdarahan, menyerap eksudat dan tidak lengket ketika melepas balutan, menghilangkan jaringan yang nekrotik dengan alami karena nekrotomi pada luka kanker sangat beresiko perdarahan (Kartika, 2015).

Dari pasien kanker payudara yang diberikan perawatan oleh Bestcare yaitu rata-rata 15-20 kunjungan setiap bulan menunjukkan luka yang membaik, ukuran luka mengecil, jumlah eksudat menurun, perdarahan terkontrol.

\section{KESIMPULAN}

Program Bestcare mampu menyadarkan kader kesehatan mengenai pemahaman kanker payudara. Kader kesehatan meningkat ketrampilannya dalam pemeriksaan payudara sendiri (SADARI) untuk screening kanker payudara. Adanya program Bestcare membuat para pasien yang mengalami nyeri dapat mempraktekkan teknik relaksasi otot progresif untuk mengurangi rasa nyeri sesuai prosedur. Pada pasien yang memiliki luka, dilakukan perawatan luka dengan teknik modern dressing sehingga menunjukkan ukuran luka yang mengecil, jumlah eksudat yang menurun dan perdarahan yang terkontrol.

Diharapkan para kader dapat berpartisipasi disetiap kegiatan peduli kanker dengan terus menggiatkan menerapkan pola hidup sehat bagi masyarakat, dapat melakukan kegiatan pendampingan saat pasien melakukan teknik mengurangi rasa nyeri (rekasasi otot progresif). Kegiatan selanjutnya diharapkan Bestcare mampu memberikan beberapa pelatihan mengenai perawatan paliatif pada perawat dan keluarga sebagai wujud usaha peningkatan kualitas hidupnya.

\section{UCAPAN TERIMA KASIH}

Penulis mengucapkan terimakasih atas terlaksananya program BESTCARE kepada:

1. Direktorat Riset dan Pengabdian Masyarakat Kementrian Riset dan Teknologi Pendidikan Tinggi Atas Dana Hibah yang didapatkan dengan Skema PPUPIK.

2. Pimpinan dan Staff Rektorat Universitas Islam Sultan Agung. 
3. Staff LPPM Universitas Islam Sultan Agung.

4. Pimpinan dan Dosen Fakultas IImu Keperawatan Unissula.

5. Warga dan Kader di Wilayah binaan Kelurahan Bandarharjo.

\section{DAFTAR RUJUKAN}

Kartika, R. W. (2015). Perawatan Luka Kronis dengan Modern Dressing. Perawatan Luka Kronis Dengan Modern Dressing, 42(7), 546-550.

Kemenkes RI. (2013). Hilangkan mitos tentang kanker. www.depkes.go.id Kemenkes RI. (2015). Panduan penatalaksanaan kanker payudara.

Ketut, N., \& Ariani, P. (2017). Kebutuhan Spiritual Pada Pasien Kanker. Lazelle-Ali, C. (2007). Psychological and physical care of malodorous fungating wounds. British Journal of Nursing, 16(Sup3), S16-S24. http://doi.org/10.12968/bjon.2007 .16.Sup3.24528

Lund-Nielsen, B., Müller, K., \& Adamsen, L. (2005). Malignant wounds in women with breast cancer: feminine and sexual perspectives. Journal of Clinical Nursing, 14(1), 56-64. http://doi.org/10.1111/j.13652702.2004.01022.x

Piggin, C., \& Jones, V. (2007). Malignant fungating wounds: an analysis of the lived experience. International Journal of Palliative Nursing, 13(8), 384391. http://doi.org/10 .12968/ijpn.2007.13.8.24537

Regan, P. O. (2007). The impact of cancer and its treatment on wound healing Tanjung, D. (2007). Perawatan luka kanker. Jurnal Keperawatan Rufaidah Sumatera Utara, 2(November), 82-89.

Utami, S. S. (2017). Aspek psikososial pada penderita kanker payudara 20(2), 65-74. http://doi.org/10.7454/jki.v20i2.503

Utari S. (2012). Pengaruh penyuluhan tentang deteksi dini kanker payudara terhadap keterampilan SADARI pada wanita usia subur di Sleman Yogyakarta. Stikes Aisyiyah Yogyakarta

Wiksuarini, E., Rochmawati, E., \& Rahmah. (2018). Spiritualitas dan kualitas hidup pasien kanker. Dinamika Kesehatan, 9(2). 